\title{
ANÁLISE DA INADIMPLÊNCIA EM UM PROGRAMA SÓCIO-TORCEDOR: O USO DO CREDIT SCORING COMO FERRAMENTA DE GESTÃO ESPORTIVA
}

\author{
Vitor Borges Monteiro \\ Doutor em Economia - CAEN/UFC \\ Universidade Federal do Ceará \\ vitorborges@ufc.br \\ Pedro Luiz Valls Pereira \\ $\mathrm{PhD}$ em Economia - London School of Economics \\ Escola de Economia de São Paulo - EESP/FGV \\ pedro.valls@fgv.br
}

\section{Resumo}

Objetivo do estudo: Os programas de fidelização de torcedores são exemplos de como os clubes adaptaram ferramentas bem-sucedidas do mundo corporativo para impulsionarem suas marcas, visando uma alternativa perene de receitas. Porém, o ambiente de volatilidade passional dos torcedores se torna um desafio na gestão esportiva. Dessa forma, o objetivo do trabalho consiste em implementar uma metodologia de Credit Scoring para avaliar o comportamento de inadimplência em um programa de sócios.

Metodologia/abordagem: O Credit Scoring é tradicionalmente difundido nas instituições bancárias para estudar o comportamento de inadimplência dos clientes, utilizando perfis cadastrais e de relacionamento para atribuir scores que mensuram o risco de inadimplência.

Originalidade/relevância: Entender o comportamento do torcedor se torna fundamental para o gestor implementar medidas promocionais que visem potencializar a fidelização.

Principais resultados: Os resultados apontam que os sócios com planos mais caros, idades mais elevadas, mesma cidade da realização dos jogos e proximidade ao estádio tem suas probabilidades de inadimplência reduzidas de forma significativa. Mesmo se tratando de um ambiente de maioria masculina, o sexo feminino se apresenta como um perfil de menor probabilidade de inadimplência. $\mathrm{O}$ fato do titular da conta de sócio possuir dependentes vinculados reduz a probabilidade de inadimplência, contrapondo-se à literatura de Credit Scoring bancário, onde o número de dependentes aumenta a probabilidade de inadimplência.

Contribuições teóricas/metodológicas: O trabalho utiliza técnicas de georreferenciamento para calcular a distância de cada sócio para o estádio, e utiliza técnica de estimação do Credit Scoring em dois estágios, com a base de perfis ativos e inativos.

Palavras-Chave: Programa de fidelização. Sócio torcedores. Futebol. Inadimplência. Credit scoring.

\section{Cite como}

American Psychological Association (APA)

Monteiro, V. B., \& Pereira, P. L. V. (2022, jan./abr.). Análise da inadimplência em um programa sócio-torcedor: o uso do credit scoring como ferramenta de gestão esportiva. PODIUM Sport, Leisure and Tourism Review, São Paulo, 11(1), 145-174.

https://doi.org/10.5585/podium.v11i1.20124. 


\title{
THE ANALYSIS OF DEFAULT IN A FAN MEMBERSHIP PROGRAM: THE USE OF CREDIT SCORING AS SPORTS MANAGEMENT TOOL
}

\begin{abstract}
Research aim: Fan membership programs are examples of how clubs adapted successful tools from corporate world to boost their brands, seeking for a perennial revenue alternative. However, the environment of passionate volatility of the fans becomes a challenge for the sports management. In this way, the aim of the work consists of implementing a Credit Scoring methodology to assess the default behavior in a fan membership program. Methodological approach: The Credit Scoring is traditionally widespread in bank institutions to study the default behavior of customers, using registration and relationship profiles to assign scores that measure the risk of default. Originality and relevance: Understanding the fan's behavior is essential for the manager to implement the promotional measures that aim to enhance the loyalty.

Main results: The results indicate that members with more expensive plans, with older ages, that live in the same city that the games are played and their proximity to the stadium, significantly reduce their probabilities to default. Even if it is a male-majority environment, the female gender presents itself as a profile with a lower probability of default. The fact that the member account holder has dependents linked reduces the probability of default, counterposing the banking Credit Scoring literature, in which the number of dependents increases the probability of default.

Theoretical and methodological contributions: The work uses georeferencing techniques to calculate the distance of each member to the stadium and uses a two-stage Credit Scoring estimation technique, based on active and inactive profiles.
\end{abstract}

Keywords: Loyalty Program. Fan membership. Soccer. Default. Credit scoring.

\section{ANÁLISIS DE INCUMPLIMIENTO EN UN PROGRAMA DE FAN SOCIO: EL USO DE LA PUNTUACIÓN DE CRÉDITO COMO HERRAMIENTA DE GESTIÓN DEPORTIVA}

\section{Resumen}

Objetivo del estudio: Los programas de fidelización de aficionados son ejemplos de cómo los clubes han adaptado herramientas exitosas del mundo empresarial para impulsar sus marcas, con el objetivo de ofrecer una alternativa de ingresos perenne. Sin embargo, el entorno de apasionada volatilidad de la afición se convierte en un desafío en la gestión deportiva. Por lo tanto, el objetivo del trabajo es implementar una metodología de Credit Scoring para evaluar el comportamiento moroso en un programa de socios.

Metodología/enfoque: El Credit Scoring se ha difundido tradicionalmente en las instituciones bancarias para estudiar el comportamiento de incumplimiento de los clientes, utilizando perfiles de registro y relación para asignar puntajes que miden el riesgo de incumplimiento.

Originalidad/relevancia: Comprender el comportamiento del aficionado es fundamental para que el gerente implemente medidas promocionales que tengan como objetivo aumentar la lealtad del cliente.

Principales resultados: Los resultados muestran que los miembros con categorías de plan más caros, edades más avanzadas, la misma ciudad donde se juegan los partidos y la proximidad al estadio, reducen significativamente sus posibilidades de incumplimiento. Incluso en el caso de un entorno mayoritariamente masculino, el género femenino se presenta como un perfil con menor probabilidad de incumplimiento. El hecho de que el titular de la cuenta del socio tenga dependientes dependientes reduce la probabilidad de incumplimiento, en contraste con la literatura de calificación crediticia bancaria, donde el número de dependientes aumenta la probabilidad de incumplimiento.

Aportes teórico/metodológicos: El trabajo utiliza técnicas de georreferenciación para calcular la distancia de cada socio al estadio y utiliza una técnica de estimación de Credit Scoring en dos etapas, basada en perfiles activos e inactivos.

Palabras clave: Programa de fidelización. Fan socio. Fútbol. Incumplimiento, pontuación de crédito. 
Monteiro, V. B., \& Pereira, P. L. V. (2022, jan./abr.). Análise da inadimplência em um programa sócio-torcedor: o uso do credit scoring como ferramenta de gestão esportiva

\section{Introdução}

A gestão empresarial vem se profissionalizando nas últimas décadas, com um mercado consumidor cada vez mais antenado com os conceitos de boas práticas de governança corporativa. Nesse sentido, diversas empresas familiares tiveram que se readequar às novas tendências e exigências do mercado. No mundo do futebol não é diferente, a atividade futebolística se desenvolveu bastante nas últimas décadas, o que vem acarretando uma mudança não apenas nas formas de organização esportiva, mas nos próprios princípios que fundamentavam a existência de clubes, torneios e federações. Antes dessa modificação estrutural, o futebol era movido pela simples paixão de seus diretores, torcedores e até mesmo atletas. Para Ribeiro (2012), a paixão nacional pelo futebol é um atavismo, uma busca por uma identificação dentro de um contexto de incompletude civilizacional. Assim, alguns mitos são estabelecidos e dificultam as mudanças, principalmente no campo empresarial.

O marco dessa mudança veio com o processo de internacionalização do mercado de atletas, no início dos anos 1990, inflacionando os salários no setor. Concomitantemente a esse processo, a Lei Pelé, em 1998, modernizou as relações trabalhistas no futebol, antes regidas pela Lei do Passe. A Lei Pelé, Lei no 9.615, de 24 março de 1998, trouxe a possibilidade da desvinculação do direito econômico e do direito federativo, mudanças que ocasionaram a necessidade do futebol se reestruturar devido ao consequente desafio da gestão dos contratos de atletas. Paralelamente a essas modificações nas relações de trabalho no futebol, leis como o Estatuto do Torcedor, Lei $\mathrm{n}^{\circ}$ 10.671, de 15 de maio de 2003, exigem cada vez mais melhores práticas, comprometimento e apreço ao torcedor, confirmando uma tendência de gestão profissional do futebol em toda sua esfera.

Entretanto, a gestão do futebol, principalmente para os clubes fora do establishment do futebol brasileiro, onde se concentra a maioria dos atletas, tem sido um desafio adicional, pois muitos desses clubes não possuem um calendário esportivo anual completo e, consequentemente, possuem uma estrutura de receita sazonal. Além disso, o clube de futebol precisa de uma estrutura organizacional, contábil e jurídica para tratar com a alta rotatividade de funcionários (atletas), causas trabalhistas e, para aqueles que aderiram ao Programa de Modernização da Gestão e Responsabilidade Fiscal do Futebol Brasileiro (Profut), Lei № 13.155 de 4 de agosto de 2015, uma competente gestão fiscal e financeira, pois, por exemplo, pela lei do Profut, os clubes devem publicar o balanço do exercício anterior até 30 de abril do subsequente ano. Segundo Umbelino, Silva, Ponte e Lima (2019) o refinanciamento das dívidas 
Monteiro, V. B., \& Pereira, P. L. V. (2022, jan./abr.). Análise da inadimplência em um programa sócio-torcedor: 0 uso do credit scoring como ferramenta de gestão esportiva

federais, com a respectiva contrapartida de transparência de divulgação contábil, não trouxe resultados econômico-financeiros e esportivos significativos nos dois primeiros anos do Profut.

Nesse contexto, torna-se fundamental na gestão de um clube de futebol um planejamento orçamentário anual capaz de equilibrar as suas contas. Entretanto, o futebol move a paixão de seus torcedores e dirigentes e, muitas vezes, após uma derrota ou desclassificação, são tomadas decisões que colapsam as finanças do clube, como mudança de treinador e/ou contratações de novos atletas fora do planejado. O desafio de separar a razão da emoção torna a gestão esportiva mais complexa que qualquer outra atividade empresarial. Segundo Rosolino (2020), o total da dívida dos 12 clubes que mais devem no futebol brasileiro, com base nos balanços de 2019, chega próximo aos $\mathrm{R} \$ 7$ bilhões.

Por sua vez, a mesma paixão que move conflitos e interesses internos na gestão esportiva desperta uma gama de oportunidades na relação com seus clientes (torcedores). Nesse sentido, surge o marketing esportivo como uma ferramenta capaz de potencializar receitas dentro de uma nova concepção de torcedor-consumidor, criando programas de fidelização, canais de comunicação exclusivos, gestão de redes sociais, lojas exclusivas, exploração de direito de arena etc. Segundo Fleury, Brashear-Alejandro e Feldmann (2014), os quatro Ps do marketing: produto, preço, praça e promoção, fatores perfeitamente adaptáveis para o mundo do futebol e que auxiliam a compreensão do consumidor esportivo.

Segundo Yang e Bruwer (2017), os programas de fidelidade buscam auferir vantagens competitivas para as empresas por meio de um maior relacionamento com os clientes, e identificou na literatura quatro categorias de fidelização: econômico, social, psicológico e personalização. Os grandes programas de fidelização estão vinculados a operadoras de cartões de crédito, oferecendo pontos que podem ser trocados por benefícios exclusivos, entretanto, qualquer empresa, de qualquer porte, pode elaborar uma estratégia voltada a administrar e fidelizar uma carteira de clientes. Os programas de fidelização no futebol, na sua forma mais simples, consistem em programas de sócios torcedores que contemplam entradas livres nos estádios mediante pagamento de mensalidades, uma espécie de venda antecipada de bilhetes que proporcionam ao clube uma previsibilidade de arrecadação, essencial no planejamento orçamentário. Na sua forma mais complexa, os planos de sócios contemplam descontos em produtos licenciados do clube, desconto em rede de estabelecimentos parceiros, acessos exclusivos etc.

Entretanto, gerenciar a inadimplência desses programas consiste em uma tarefa cautelosa, visando administrar a frustração momentânea do torcedor após os resultados 
Monteiro, V. B., \& Pereira, P. L. V. (2022, jan./abr.). Análise da inadimplência em um programa sócio-torcedor: 0 uso do credit scoring como ferramenta de gestão esportiva

esportivos. Em caso de inadimplência, o clube romper os laços de lealdade através do acionamento dos órgãos de proteção de crédito pode abalar o conceito do programa. Segundo Leal (2011), quando o Vasco da Gama atingiu a marca de $83 \%$ de inadimplência, em 2011, o clube investiu em transparência, apresentando os números para a torcida como forma de provocação.

Nesse cenário, o presente estudo consiste em analisar o comportamento da inadimplência do programa de sócio-torcedores do Ferroviário Atlético Clube - CE, aplicando a metodologia de Credit Scoring para compreender como os perfis demográficos e espaciais se comportam dentro da estrutura de inadimplência do programa. Essa metodologia é bastante consolidada dentro das instituições financeiras, gerando scores para os clientes que retratam o risco de inadimplência. Além disso, será abordada a questão da seleção amostral em modelos de escoragem, como discutido por Greene (1998). As principais variáveis para mensurar o comportamento da inadimplência serão: tipo de plano, dependentes, idade, gênero, cidade e distância para o estádio. Serão utilizadas técnicas de georreferenciamento dos dados cadastrais para mapear as distâncias dos sócios para o Estádio Presidente Vargas, em Fortaleza-CE, local de maior incidência de jogos do clube em estudo. Vale destacar que a base de dados foi extraída em Abril de 2020, então, os efeitos da pandemia de COVID-19 não se refletem nos índices de inadimplência deste estudo.

\section{Revisão de literatura}

Carvalho, Molletta, Stinghen e Knaut (2013) discutem a evolução do marketing para compreender o torcedor como consumir. Discutem que, diferentemente de outros segmentos de mercado, a indústria do esporte tem características de fidelidade e lealdade na relação empresa e cliente, ou seja, clube e torcedor. A identificação que o torcedor possui com as marcas do seu clube o envolve emocionalmente para realizar compras de produtos ou adquirir um plano de associação. Entretanto, essa fidelidade não produzirá satisfação por consequência, necessitando que o clube identifique quais os pontos de melhoria para atender seus torcedores de forma satisfatória. Dessa forma, os autores propuseram identificar a satisfação dos consumidores/sócio-torcedores do Paraná Clube, com os benefícios e serviços oferecidos pelo programa de fidelidade. A pesquisa foi realizada através da aplicação de questionário em 416 sócios, e as principais constatações foram que o sócio estava satisfeito com os planos de 
associação e com os preços cobrados, porém insatisfeito com a estrutura do estádio, os locais de vendas e os produtos disponibilizados pelo Paraná Clube.

O programa sócio torcedor do Sport Clube Internacional de Porto Alegre-RS é um dos mais bem-sucedidos do país. Em 2009, tornou-se o primeiro clube brasileiro a romper a barreira de 100 mil associados. Com base nessa experiência exitosa, Xavier (2010) observou os mecanismos adotados pelo clube para conseguir e manter a fidelização dos clientes (torcedores) nessa nova fase do futebol-negócio. Discute que a fidelização do torcedor se trata de uma modalidade especial de pertencimento clubístico sintonizada com o empresariamento e a comercialização do espetáculo futebolístico. A metodologia utilizada mescla técnicas de pesquisa qualitativa e quantitativa, buscando informações em livros, jornais, revistas e sites. Os resultados mostram que o programa sócio torcedor se apresenta como uma excelente fonte de renda para o clube, pois as mensalidades pagas pelos torcedores associados representam uma garantia de receitas de aproximadamente $30 \%$ do total de receitas do clube

Além disso, os autores enaltecem que o clube gaúcho adotou o modelo europeu, que se caracteriza pelo fato dos sócios participarem mais efetivamente da vida do clube, inclusive tendo direito a voto, além de outros benefícios a entrada no estádio sem ingresso, preferência na compra dos ingressos e descontos especiais na compra de produtos licenciados do clube. Em relação à demografia dos sócios, 50\% estão na capital, 15\% na região metropolitana, 30\% no interior e 5\% estão fora do estado do Rio Grande Sul.

Ainda sobre o Sport Club Internacional, Bandarra (2017) buscou informações no Portal da Transparência do clube sobre o número de associados em dia, inadimplentes, por sexo, pela idade e pela localidade, em três diferentes momentos do time. Percebeu-se, com os resultados, que a inadimplência e o perfil por idade do quadro social têm uma forte variação atrelada ao rendimento da equipe.

No que se refere ao perfil dos associados, percebeu-se que grande parte deles é do sexo masculino, representando, em média, aproximadamente $78 \%$ do quadro. Quanto à idade dos societários, foi identificada uma grande variabilidade na idade do quadro quando analisados os diferentes momentos da equipe. Os torcedores de idade média, entre 16 e 50 anos, tem uma propensão a ter uma atuação mais elástica, participando do quadro social quando a equipe possui bons resultados e deixando-o quando estão descontentes com o rendimento do time. No grupo dos torcedores mais velhos, acima de 50 anos, foi percebido um comportamento contrário, com o aumento do quadro social conforme os resultados em campo pioram. No que diz respeito ao perfil de distribuição geográfica dos sócios do SC Internacional, percebeu-se um 
Monteiro, V. B., \& Pereira, P. L. V. (2022, jan./abr.). Análise da inadimplência em um programa sócio-torcedor: 0 uso do credit scoring como ferramenta de gestão esportiva

aumento da participação de Porto Alegre e região metropolitana quando a equipe apresentava melhor resultado, representando mais da metade do quadro social. Isso se deve ao fato dos torcedores dessas regiões terem interesse em frequentar as partidas decisivas no período.

Silva, Furin, Conejero, André e Bougleux (2017) analisaram os programas sóciotorcedor de Corinthians, Palmeiras, Internacional, São Paulo, Grêmio, Cruzeiro, Flamengo, Atlético Mineiro e Santos, principalmente em relação aos benefícios concedidos aos sócios, com intuito de comparar e propor melhorias ao programa "Todos pelo Voltaço" do Volta Redonda Futebol Clube. Os autores evidenciaram que os grandes clubes, apesar do relativo sucesso alcançado, ainda apresentam baixa representatividade de sócios em relação ao total de torcedores declarados. Existe uma série de benefícios comuns a todos os programas, como desconto em ingressos e rede de parceiros, e poucas peculiaridades, com a exceção do Internacional, que oferece direito a voto. A proposta do autor é que o Volta Redonda utilize o CRM (Customer Relationship Management, em português, Gestão de Relacionamento com o Cliente), metodologia que sugere uma análise detalhada dos perfis de associados para oferecer benefícios específicos e, consequentemente, potencializar a base de sócios. Além disso, os autores reconhecem a dificuldade de implementar a metodologia sugerida em um clube mediano, devido às fragilidades dos relatórios.

Em relação às dificuldades dos clubes medianos adotarem as estratégias de sóciotorcedor, Azevedo (2013) contatou doze clubes esportivos de futebol profissional que participaram do Campeonato Brasiliense da $1^{\text {a }}$ divisão, em 2013, e constatou a necessidade de melhor formação e capacitação dos gestores, de maneira a conhecer melhor os conceitos da gestão profissional focada na identificação e percepção de novas oportunidades

Souza Monteiro e Ribeiro (2019) pesquisaram torcedores dos 20 principais clubes da série A do Campeonato Brasileiro de 2016. Buscaram identificar a estrutura de valor percebido por distintas características sociodemográficas em um conjunto de atributos oferecidos pelos programas sócio-torcedor, como preço, desconto no ingresso, benefícios em rede parceira, compra antecipada, dependentes e área privilegiada, e propor um modelo elaborado com Rede Bayesiana (RB) para identificar o plano ideal para públicos distintos. Os dados foram coletados através de um survey online, totalizando 436 observações, após testes de validação. Foram analisados com Análise Conjunta (AC) e Rede Bayesiana (RB), e verificou-se que o desconto nos ingressos e os preços são os atributos de maior valor para os torcedores de forma geral. Entretanto, o estrato de menor renda familiar e nível de escolaridade valorizou mais os benefícios oferecidos pelo programa, como rede parceira. Já os jovens até 17 anos valorizaram 
Monteiro, V. B., \& Pereira, P. L. V. (2022, jan./abr.). Análise da inadimplência em um programa sócio-torcedor: 0 uso do credit scoring como ferramenta de gestão esportiva

mais a compra antecipada. Outro ponto a destacar é que as torcedoras possuem o mesmo ordenamento de preferência dos homens, quanto aos atributos oferecidos pelo programa sóciotorcedor.

Na literatura internacional, destaca-se o trabalho de Desarbo (2010), que discute sobre a indústria do esporte nos EUA ser um dos dez maiores setores de negócios, com sua principal fonte de receita proveniente de fãs do esporte, porém com poucos estudos sobre o comportamento do torcedor-consumidor. Para preencher essa lacuna existente na literatura, os autores se propuseram a observar a paixão esportiva por um viés multidimensional, indo além das despesas financeiras dos seus fãs e observando também a alocação de tempo e esforço empreendido para acompanhar o esporte. Assim, o objetivo da pesquisa foi descobrir os aspectos multidimensionais das manifestações observadas de avidez dos fãs e explorar a natureza da heterogeneidade dessas expressões. Os dados foram coletados de uma amostra de estudantes fãs de futebol de uma universidade nos Estados Unidos; no total, 307 questionários foram respondidos. Trinta e cinco expressões diferentes de avidez dos fãs foram descobertas relacionadas a como esses torcedores seguem e apoiam seu time de futebol, as expressões comuns a mais de $80 \%$ dos alunos foram: frequentar pelo menos um jogo em casa; ler sobre o time de futebol no jornal da escola; assistir a um jogo de futebol na TV em casa; usar a internet para acompanhar o futebol ou a liga; piquenique no estádio antes dos jogos; participar de celebrações ou festas após o jogo; usar as cores da escola (roupas) durante o jogo de futebol. Como conclusão de um modelo de desdobramento multidimensional (MDD) de escolha discreta, foram descobertas quatro dimensões latentes à expressão de avidez: participação em campo, acompanhamento passivo, vínculo social e compras.

Na mesma linha de Desarbo (2010), Biscaia et al. (2016) examinaram as diferenças nas percepções do valor da marca da equipe entre sócios e não sócios, e o papel preditivo das dimensões do valor da marca nas intenções comportamentais. Os dados foram coletados de fãs de uma liga profissional de futebol e analisados através de CFA (Confirmatory Factor Analysis), onde evidenciaram que os grupos de sócios e não sócios possuem diferenças significativas nas médias latentes em relação a escala de percepção de valor de marca, mensurado através de variáveis como interação social, atributos organizacionais, sucesso da equipe, treinador principal, frequência no estádio etc.

Segundo Llopis-goig (2012), tradicionalmente, estudos acadêmicos na Europa examinam os efeitos da violência nas multidões ou das implicações dos sentimentos nacionalistas e regionalistas pelos clubes. As análises recentes também se estenderam para 
Monteiro, V. B., \& Pereira, P. L. V. (2022, jan./abr.). Análise da inadimplência em um programa sócio-torcedor: 0 uso do credit scoring como ferramenta de gestão esportiva

incluir questões de gênero (e o processo de construção da masculinidade, em particular) e uma série de estudos sobre o racismo e a xenofobia, os quais prejudicaram os espetáculos nos últimos anos. Pouca atenção, no entanto, tem sido dedicada ao estudo do comportamento dos torcedores diante das transformações comerciais que revolucionaram o futebol. Com essa lacuna em mente, o autor se propõe a examinar o comportamento de torcedores no futebol espanhol, sob perspectiva empírica, e extrair as consequências sociais dos processos de mercantilização do futebol no discurso dos torcedores. Em outras palavras, o autor procura compreender se a venda de clubes para milionários estrangeiros ou a utilização excessiva de instrumentos comerciais na relação com os torcedores influenciaram de alguma forma o conceito dos fãs do esporte.

O estudo foi baseado na entrevista de 19 especialistas esportivos sobre o Valencia FC e do Levante UD, dois clubes da cidade de Valencia, porém com características muito diferentes. Segundo dados da temporada 2010/2011, enquanto o Valencia possuía orçamento de 130 milhões de euros e 5,2\% da torcida espanhola ( $5^{\circ}$ clube em títulos), o Levante possuía um modesto orçamento de 20 milhões e apenas 0,2\% da preferência da torcida. Entretanto, um resultado importante encontrado foi que os torcedores de ambos os clubes possuem sentimento de pertence que independe destes serem vendidos para investidores estrangeiros ou se transformarem em sociedades anônimas, além de consumirem com frequência produtos lançados pelos clubes.

Hamil, Walters e Watson (2010) apresentaram um estudo de caso aprofundado da governança do FC Barcelona entre 1978 e 2008. Nos anos 2000-2003, o clube apresentou uma reforma radical da sua governança, modificando sua estrutura social para captar sócios e investidores fora da Catalunha, aproveitando-se do momento de globalização do futebol espanhol. Os princípios básicos da reforma foram pautados em quatro áreas estratégicas principais: a priorização do sucesso esportivo; a reafirmação da democracia de associados e melhorias na transparência da governança do clube; a implementação de uma estratégia comercial com o objetivo de gerar aumento de receitas; e o desenvolvimento de uma série inovadora de iniciativas de responsabilidade social corporativa. A análise concluiu que a reestruturação da governança impulsionou a capacidade de competir em termos financeiros e esportivos, e sugeriu que este modelo poderia também ser adotado na Premier League inglesa.

Moreira e Hijós (2013) discutiram as estratégias que algumas instituições esportivas na Argentina adotaram para modernizar sua gestão. Os autores repercutem que as lideranças que promoveram o processo de modernização foram empresários de renome no meio empresarial, que conseguiram ingressar no campo da política esportiva com uma trajetória mais curta, em 
Monteiro, V. B., \& Pereira, P. L. V. (2022, jan./abr.). Análise da inadimplência em um programa sócio-torcedor: 0 uso do credit scoring como ferramenta de gestão esportiva

comparação com as lideranças anteriores, graças à exposição de seu capital econômico e capital social. Os autores entrevistam os gestores do Club Atlético Boca Junior e Club Atlético Independiente. Para Mauricio Macri, ex-gestor do Boca Junior e depois presidente da Argentina, a modernização do clube passa pela valorização dos sócios, pois a base de sócios representa um capital intangível para o clube que viabiliza uma série de alternativas econômicas através de parcerias.

Macri, Ballvé e Ibarra (2009) retratam o ciclo da gestão Macri no Boca Juniors, e destacam como o planejamento, ferramentas gerenciais e o foco no negócio impulsionaram a marca do clube. Os autores relatam que, quando Macri decidiu assumir o Boca Juniors, sua primeira iniciativa foi ligar para quinze ex-jogadores mais famosos do clube e fazer uma pergunta única, mas muito esclarecedora, do tipo que não pode ser respondida de forma evasiva: “O que deu errado nestes últimos quinze anos?". A coincidência foi absoluta: "Perdemos nossa identidade". O segundo passo foi implementar uma estratégia com base em conceitos gerenciais, como missão, organização, princípios e metas, elencados respectivamente como: 1) Colocar o Boca entre os cinco maiores clubes do futebol mundial; 2) Ordem da instituição, porque sem ordem nada pode funcionar: nem um clube, nem uma empresa, nem uma cidade, nem um país; 3) Criar um clube que estaria acima, em poder e prestígio, dos dirigentes, dos treinadores e dos jogadores; 4) Reunir uma equipe de jogadores que se adaptassem às exigências do Boca, com ausência de estrelas (Macri, Ballvé \& Ibarra, 2009).

\section{Descrição da base de dados e aspectos demográficos e espaciais}

A presente pesquisa tem por objetivo estimar scores que medem o risco de inadimplência em um programa sócio-torcedor, através de uma abordagem quantitativa econométrica com modelos de escoragem. A modelagem será tratada na próxima seção, enquanto nesta será feita a caracterização descritiva da base de dados dos sócios do Ferroviário Atlético Clube.

O Ferroviário Atlético Clube, time de futebol da cidade de Fortaleza, fundado em 1933, por funcionários da antiga Rede de Viação Cearense (RVC), possui nove títulos estaduais e um título brasileiro da Série D. Considerado o terceiro clube do Estado do Ceará, disputa a série C do Campeonato Brasileiro em 2021 e ocupa a posição 57 no ranking de clubes da CBF em 2021. Segundo Gomes (2014), a média de público nos estádios, excluindo jogos contra os rivais da capital, Ceará e Fortaleza, oscila entre 320 e 3794 espectadores, ao longo de 47 anos 
Monteiro, V. B., \& Pereira, P. L. V. (2022, jan./abr.). Análise da inadimplência em um programa sócio-torcedor: 0 uso do credit scoring como ferramenta de gestão esportiva

analisados (1967 a 2014). Além disso, os picos de alta e baixa acompanham o desempenho esportivo da equipe. Na final do Campeonato Brasileiro da Série D, quando o clube consagrouse campeão, em 2018, foram 6.407 pagantes.

O programa sócio-torcedor do Ferroviário, chamado "Sócio Coral" (www.sociocoral.com.br), repaginado e profissionalizado em 2019 para as disputas do Campeonato Brasileiro da Série C, possui quatro modalidades de planos de adesão: Campeão Cearense, no valor de R \$ 10,00; Campeão dos Campeões, no valor de R \$ 50,00; Campeão Brasileiro, no valor de R \$ 70,00 e; Conselheiro, no valor de R \$200,00. Os nomes dos planos fazem alusão aos títulos conquistados pelo clube. O plano Campeão Cearense é o único que não possui direito à entrada no estádio, idealizado para atender torcedores fora da cidade de Fortaleza, ou mesmo oferecer uma alternativa democrática de adesão. Os demais planos possibilitam a entrada no estádio, mas, à medida que aumenta o valor do plano, há mais vantagens em termos de acesso a setores na praça esportiva e descontos em produtos na loja oficial "Ferrão Store". Pelo novo Estatuto do clube, reformulado em 2012, todos os sócios contribuintes gozam de direitos estatutários após 3 (três) anos de contribuição, além disso, o plano Conselheiro goza de benefícios estatutários específicos.

Um quinto plano chamado "Tubarãozinho", em alusão ao mascote do clube, foi criado para crianças de até 12 anos. Vale ressaltar que crianças nessa faixa etária possuem direito à entrada gratuita no estádio na forma da Lei, entretanto, existe uma burocracia para a retirada do ingresso de gratuidade. As crianças no plano Tubarãozinho são vinculadas a um sócio titular nos demais planos, então, são consideradas dependentes. O sócio titular paga $\mathrm{R} \$ 10,00$ para manter um dependente "Tubarãozinho" na sua conta e possui a vantagem de evitar burocracia na retirada do ingresso de gratuidade para seus dependentes, como filas e horários específicos. A base de dados possui 115 cadastros nessa categoria, porém não foram considerados na amostra por não possuírem autonomia financeira.

A administração do programa é feita pela empresa Dataclick Agência Digital, especializada em soluções nesse segmento de mercado e administradora de programas semelhantes em diversos clubes no Brasil. A plataforma de acesso possibilita três formas de pagamento: crédito recorrente, cartão de crédito e boleto bancário. A tabela 1 apresenta a distribuição dos sócios-torcedores em cada plano. 
Monteiro, V. B., \& Pereira, P. L. V. (2022, jan./abr.). Análise da inadimplência em um programa sócio-torcedor: o uso do credit scoring como ferramenta de gestão esportiva

Tabela 1.

Distribuição da Base de Sócios-Torcedores Por Plano De Adesão, Estratificado Pelo Status Ativo, Inativo E Inadimplência, Com Respectivas Médias De Idade e Percentual de Gênero

\begin{tabular}{|c|c|c|c|c|c|}
\hline $\begin{array}{l}\text { Plano } \\
\text { Observações (\%) }\end{array}$ & Status & Obsev. & $\begin{array}{c}\text { Média de } \\
\text { Idade (anos) }\end{array}$ & $\begin{array}{c}\% \\
\text { Mulheres }\end{array}$ & $\begin{array}{c}\% \\
\text { Homens }\end{array}$ \\
\hline Campeão Cearense & Ativo & 109 & 41,71 & $15.6 \%$ & $84.4 \%$ \\
\hline \multirow{2}{*}{$287(20,04 \%)$} & Inadimplente & 0 & --- & $0.0 \%$ & $0.0 \%$ \\
\hline & Inativo & 178 & 41,44 & $10.1 \%$ & $89.9 \%$ \\
\hline Campeão dos Campeões & Ativo & 425 & 44,26 & $14.1 \%$ & $85.9 \%$ \\
\hline \multirow[t]{2}{*}{$820(57,26 \%)$} & Inadimplente & 223 & 42,73 & $15.7 \%$ & $84.3 \%$ \\
\hline & Inativo & 172 & 40,43 & $11.0 \%$ & $89.0 \%$ \\
\hline Campeão Brasileiro & Ativo & 159 & 48,35 & $10.1 \%$ & $89.9 \%$ \\
\hline \multirow[t]{2}{*}{$282(19,7 \%)$} & Inadimplente & 62 & 43,71 & $14.5 \%$ & $85.5 \%$ \\
\hline & Inativo & 61 & 44,01 & $9.8 \%$ & $90.2 \%$ \\
\hline Conselheiro & Ativo & 33 & 50,69 & $9.1 \%$ & $90.9 \%$ \\
\hline \multirow[t]{2}{*}{$43(3 \%)$} & Inadimplente & 8 & 45,99 & $0.0 \%$ & $100.0 \%$ \\
\hline & Inativo & 2 & 59,75 & $0.0 \%$ & $100.0 \%$ \\
\hline Todos os planos & Ativo & 726 & 45,06 & $13.2 \%$ & $86.8 \%$ \\
\hline \multirow[t]{2}{*}{$1432(100 \%)$} & Inadimplente & 293 & 43,03 & $15.0 \%$ & $85.0 \%$ \\
\hline & Inativo & 413 & 41,49 & $10.4 \%$ & $89.6 \%$ \\
\hline \multirow{2}{*}{\multicolumn{2}{|c|}{ Média de Idade (em anos) }} & 1432 & 43,61 & $12,8 \%$ & $87,2 \%$ \\
\hline & & & & 38,81 & 44,31 \\
\hline
\end{tabular}

Fonte: Elaboração dos autores.

A base de dados do programa sócio-torcedor do Ferroviário foi fornecida pela secretaria do clube, com recorte em abril de 2020, portanto, os efeitos da inadimplência causados pela pandemia de COVID-19 não são capturados na análise. Observem na Tabela 1 que a base de dados contempla 1432 sócios-torcedores inscritos. O plano com maior incidência de torcedores consiste no Campeão dos Campeões, com 57,26\% dos cadastros, pois este plano representa o mais acessível dentre aqueles que oferecem acesso livre ao estádio. Do total de inscritos no programa, 726 são ativos (50,7\%), 293 são inadimplentes (20,46\%) e 413 são inativos $(28,84 \%)$. Os inativos representam aqueles torcedores que fizeram seu cadastro na plataforma, mas não concluíram o processo de pagamento; já os inadimplentes representam aqueles com alguma parcela em atraso. Notem que na categoria Campeão Cearense não existe nenhuma inadimplência, fato explicado por esta categoria não possuir a opção de crédito recorrente e boleto bancário, apenas cartão de crédito com o pagamento total da anuidade.

Ainda na Tabela 1, observem que a média de idade total dos inscritos no programa é de 43,61 anos, com os sócios ativos possuindo uma média de 45,06 anos, superior aos demais status. Notem também que as médias de idade dos sócios de todos os status (ativo, inativo e inadimplente) aumentam com os planos de sócios. A média de idade dos planos são: 41,55 anos 
Monteiro, V. B., \& Pereira, P. L. V. (2022, jan./abr.). Análise da inadimplência em um programa sócio-torcedor: o uso do credit scoring como ferramenta de gestão esportiva

para o plano Campeão Cearense, 43,04 anos para o plano Campeão dos Campeões, 46,39 anos para o plano Campeão Brasileiro e 50,24 anos para o plano Conselheiro.

Em relação ao percentual de mulheres, em nenhum estrato é observado um percentual superior a 15,6\% (índice de mulheres ativas no plano Campeão Cearense). Vale ressaltar que no total de todos os planos, o percentual de mulheres inadimplentes (15\%) é superior ao percentual de mulheres ativas $(13,2 \%)$, ocorrendo o oposto para os homens, com uma proporção maior de ativos frente aos inadimplentes, $86,8 \%$ contra $85 \%$. Eximindo os planos extremos, Campeão Cearense que não possui índices de inadimplência e Conselheiro que possui poucas observações de mulheres, esse comportamento da maior inadimplência das mulheres é verificado nos planos centrais.

Por essa análise descritiva, seria possível inferir que as mulheres seriam mais inadimplentes que os homens, porém, a média de idade das 183 mulheres cadastradas no programa equivale a 38,81 anos, inferior aos 44,31 anos dos homens. Então, as mulheres são mais inadimplentes pela questão de gênero ou há influência da idade nessa base de dados? Essa resposta apenas poderá ser elucidada através de uma especificação econométrica.

Existem dois momentos de decisão no programa, o primeiro concluir a etapa de cadastramento e pagamento e o segundo permanecer ativo. Para estudar o impacto das variáveis sobre a inadimplência, retiram-se da amostra os 413 cadastros inativos, pois estes não completaram a etapa final de pagamento, restando na análise 1019 sócios torcedores divididos entre 726 ativos $(71,25 \%)$ e 293 inadimplentes $(28,75 \%)$. Observa-se nesse novo recorte, apresentado na Tabela 2, que a proporção de planos do tipo Campeão Cearense reduziu de $20,04 \%$ para $10,7 \%$, e aumentou a proporção de planos do tipo Campeão dos Campeões de $57,26 \%$ para $63,59 \%$, enquanto os demais planos mantiveram-se em proporções estáveis. 
Monteiro, V. B., \& Pereira, P. L. V. (2022, jan./abr.). Análise da inadimplência em um programa sócio-torcedor: o uso do credit scoring como ferramenta de gestão esportiva

Tabela 2.

Distribuição da Base de Sócio-Torcedores Por Plano de Adesão, Estratificado Pelo Status Ativo e Inadimplência, Com Respectivas Médias de Idade e Percentual de Gênero

\begin{tabular}{|c|c|c|c|c|c|c|}
\hline $\begin{array}{l}\text { Plano } \\
\text { Observações (\%) }\end{array}$ & Status & Observ. & Perc $\%$ & $\begin{array}{c}\text { Média de } \\
\text { Idade (anos) }\end{array}$ & $\begin{array}{c}\% \\
\text { Mulheres }\end{array}$ & $\%$ Homens \\
\hline Campeão Cearense & Ativo & 109 & $100 \%$ & 41,71 & $15,6 \%$ & $84,4 \%$ \\
\hline $109(10,7 \%)$ & Inadimplente & 0 & $0 \%$ & -- & $0,0 \%$ & $0,0 \%$ \\
\hline Campeão dos Campeões & Ativo & 425 & $65,59 \%$ & 44,26 & $14,1 \%$ & $85,9 \%$ \\
\hline $648(63,59 \%)$ & Inadimplente & 223 & $34,41 \%$ & 42,73 & $15,7 \%$ & $84,3 \%$ \\
\hline Campeão Brasileiro & Ativo & 159 & $71,95 \%$ & 48,35 & $10,1 \%$ & $89,9 \%$ \\
\hline $221(21,69 \%)$ & Inadimplente & 62 & $28,05 \%$ & 43,71 & $14,5 \%$ & $85,5 \%$ \\
\hline Conselheiro & Ativo & 33 & $80,49 \%$ & 50,69 & $9,1 \%$ & $90,9 \%$ \\
\hline $41(4,02 \%)$ & Inadimplente & 8 & $19,51 \%$ & 45,99 & $0,0 \%$ & $100,0 \%$ \\
\hline Todos os planos & Ativo & 726 & $71,25 \%$ & 45,06 & $13,2 \%$ & $86,8 \%$ \\
\hline $1019(100 \%)$ & Inadimplente & 293 & $28,75 \%$ & 43,03 & $15,0 \%$ & $85,0 \%$ \\
\hline $\begin{array}{r}\text { Tota } \\
\text { Média de Idad }\end{array}$ & anos) & 1019 & $100 \%$ & 44,48 & $\begin{array}{c}13,74 \% \\
38,99\end{array}$ & $\begin{array}{c}86,26 \% \\
45,36\end{array}$ \\
\hline
\end{tabular}

Fonte: Elaboração dos autores.

Notem que os percentuais de inadimplência reduzem à medida que aumenta o valor do plano, as médias de idade aumentam à medida que aumenta o valor do plano, as médias de idade dos ativos são maiores que a média de idade dos inadimplentes e as mulheres possuem maiores percentuais de inadimplência (geral e dentro dos planos centrais). Porém, com a retirada dos cadastros inativos da base, observa-se uma maior participação das mulheres no programa, um aumento de 12,8\% para 13,74\%, além disso, as médias de idade também aumentam, tanto no grupo de mulheres como no grupo de homens.

A diferença de perfil demográfico, sem considerar os inativos, justificará uma análise com especificação econométrica em dois estágios, capturando o efeito do viés de seleção amostral. Isso porque a inadimplência populacional pode estar sub ou superestimada ao subtrair potenciais sócios da amostra, claramente com diferenças demográficas representativas.

A análise espacial dos dados consiste em mapear os sócios de acordo com os endereços informados no ato de cadastro. Do total de 1432 cadastros, 1106 estão na cidade de Fortaleza $(77,23 \%)$ e 326 fora da cidade de Fortaleza (22,77\%). Desses perfis fora da cidade de Fortaleza, 135 estão localizados nos 18 municípios que compõem a Região Metropolitana, com destaque para os municípios de Caucaia (56 cadastros) e Maracanaú (40 cadastros). Entre as cidades com perfis fora da Região Metropolitana, destacam-se Brasília-DF, com 10 cadastros, e Juazeiro do Norte-CE, com 6 cadastros 
Figura 1.

Mapa Categorizado Com a Distribuição dos Sócios-Torcedores por Bairro

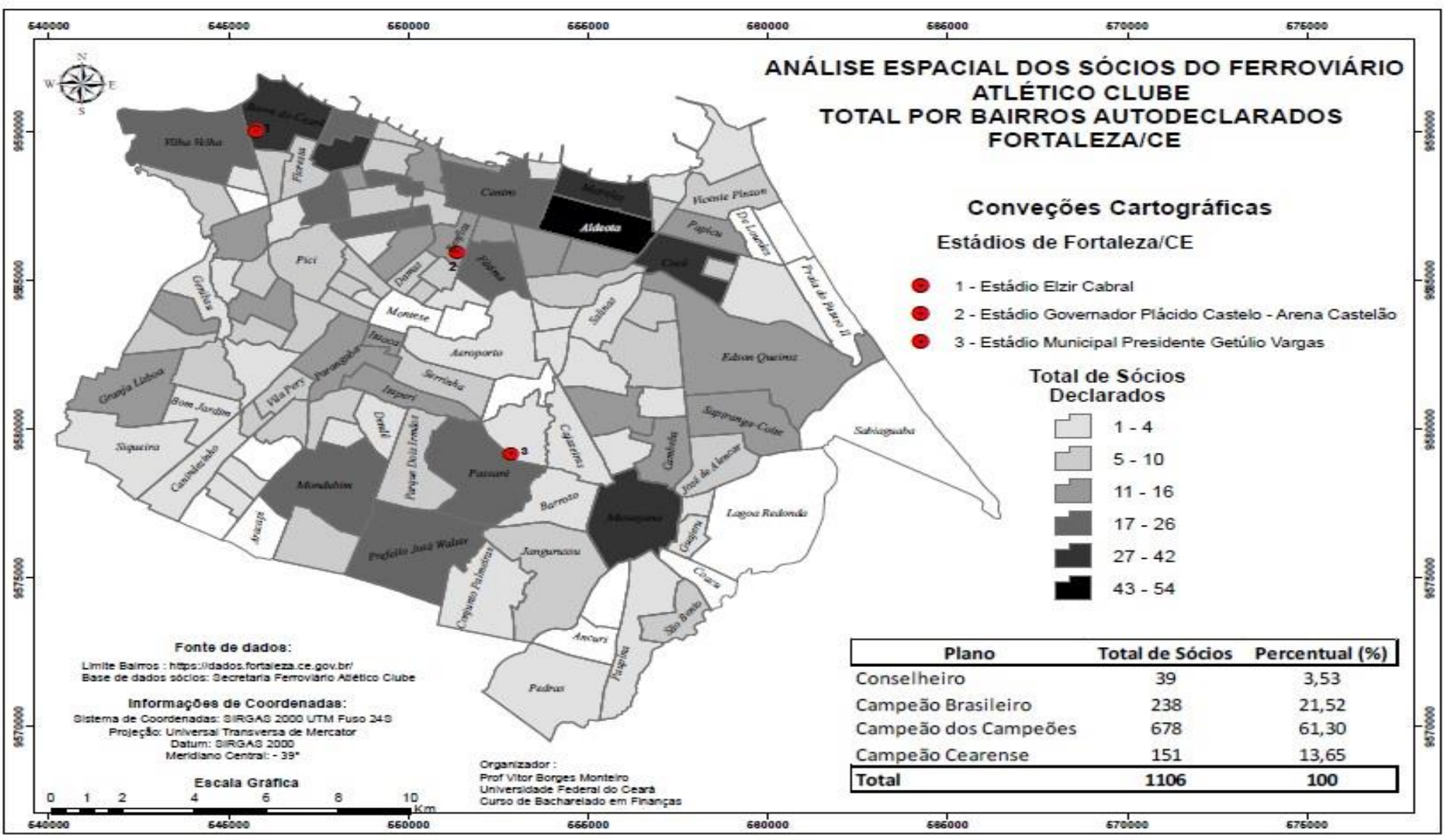

Fonte: Elaboração dos autores. 
Figura 2.

Mapa de Kernel Com a Distribuição Espacial dos Sócios-Torcedores por km²

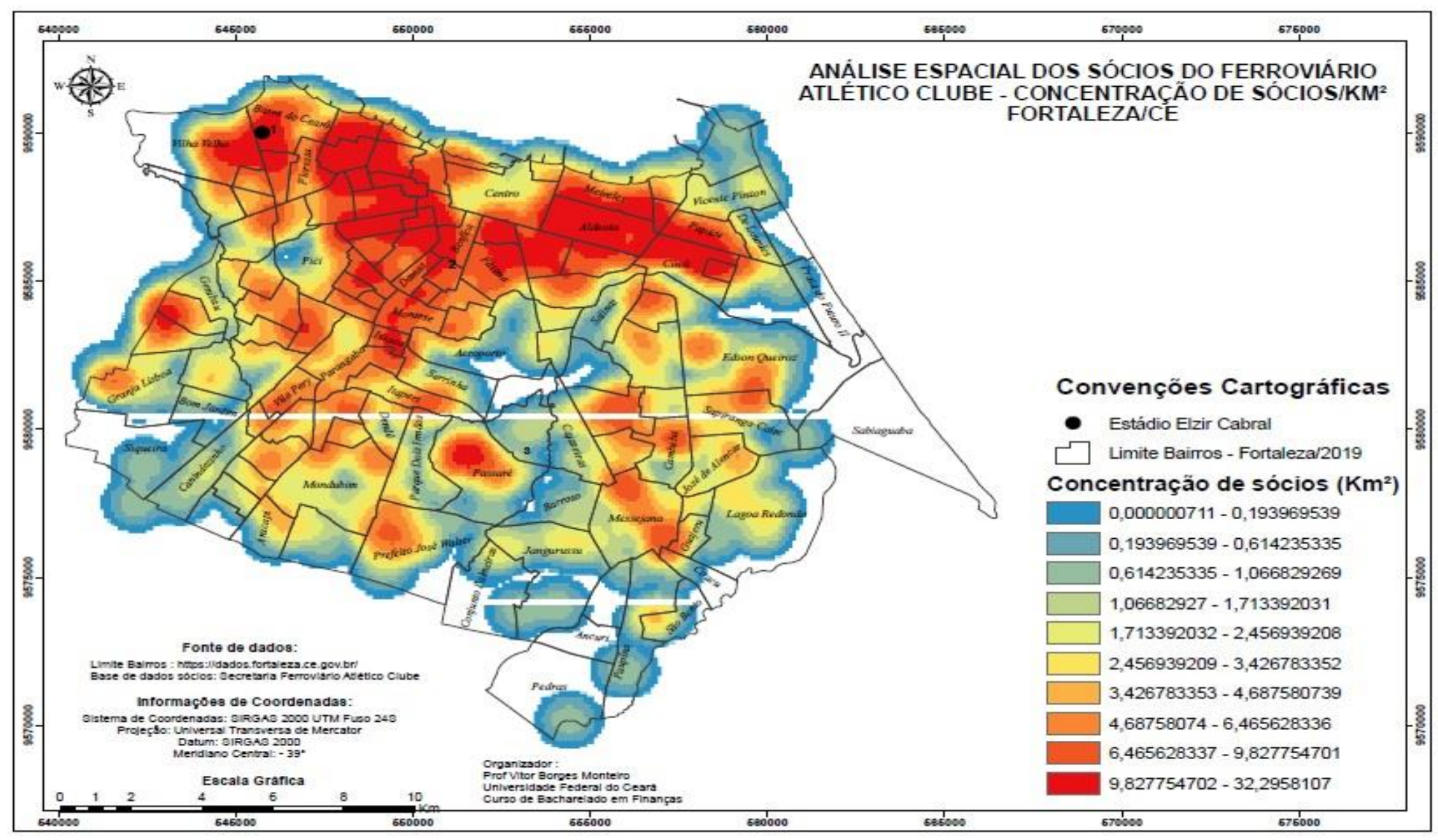

Fonte: Elaboração dos autores. 
Figura 3.

Mapa de Análise de Distância dos Bairros em Relação aos Três Estádios da Capital Cearense

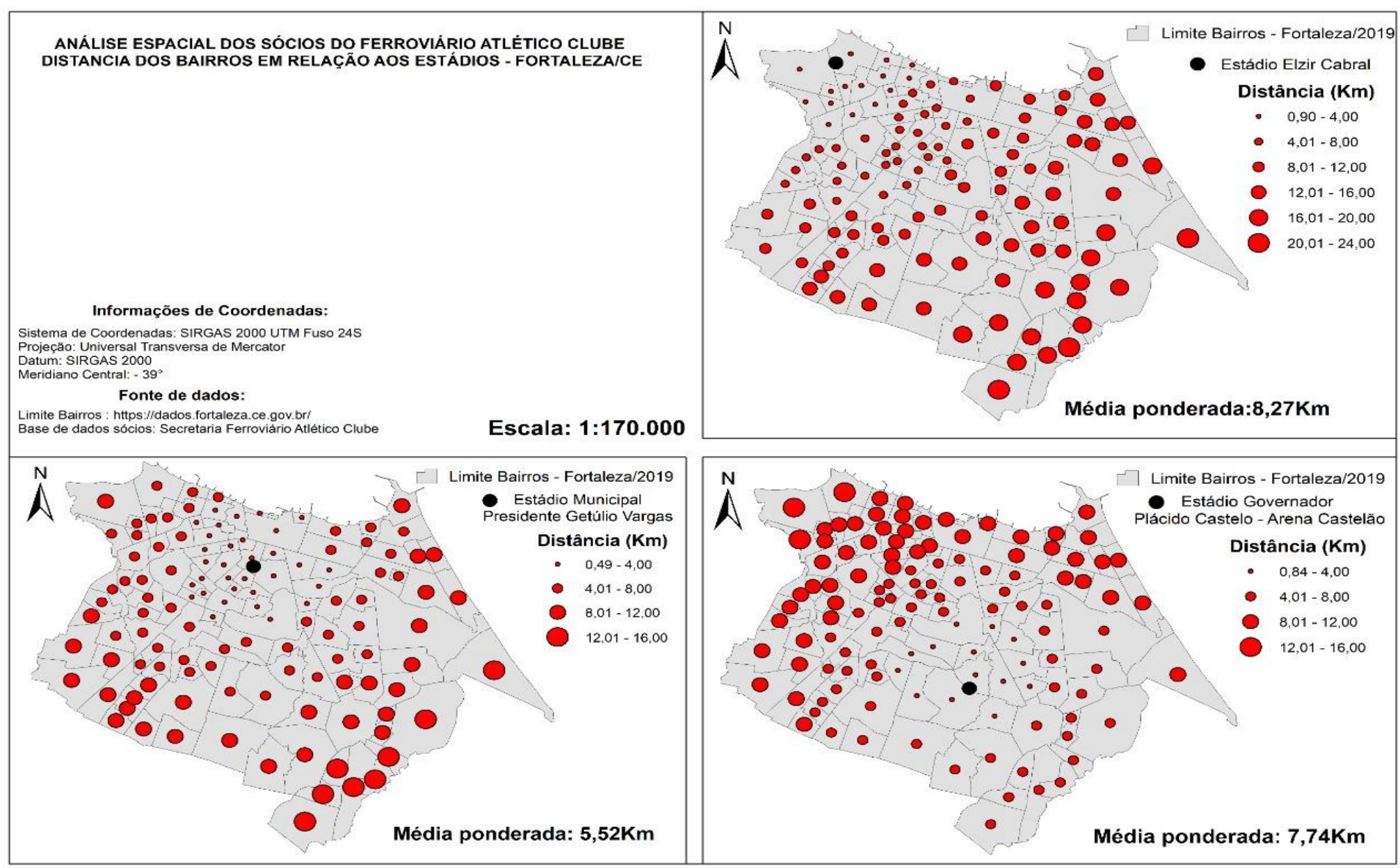

Fonte: Elaboração dos autores. 
Os resultados para a cidade Fortaleza podem ser visualizados nas Figuras 1, 2 e 3. A Figura 1 mostra a distribuição espacial dos sócios pelos 122 bairros da cidade de Fortaleza, onde apenas 15 bairros não apresentaram incidência de sócios. Através do mapa categorizado da Figura 1, é possível verificar que os dois bairros com maior concentração de sócios são Aldeota e Barra do Ceará, este último se refere ao bairro onde está localizada a sede administrativa e o Estádio Elzir Cabral, de propriedade do clube.

Vale destacar que a região da Barra do Ceará, onde se localiza o Estádio Elzir Cabral, possui baixos indicadores de renda e IDH e, mesmo assim, destaca-se com uma grande densidade de sócios. Isso se deve pela região historicamente possuir uma grande concentração de torcedores, pois as oficinas da antiga Rede Ferroviária Nacional (REFFSA) encontram-se nessa região.

A Figura 2 se refere ao mapa de Kernel, que utiliza a camada vetorial de 1106 pontos do mapa (localização dos sócios ativos, inativos e inadimplentes na cidade de Fortaleza) para apresentá-los em termos de concentração por $\mathrm{km}^{2}$. Essa análise permite visualizar a densidade da distribuição espacial, onde as regiões central e norte destacam-se em nível de incidência.

A Figura 3 apresenta a análise espacial de distância entre os sócios e o estádio. São calculadas as distâncias de todos os bairros em relação aos bairros onde estão localizados os três principais estádios da capital cearense: Estádio Elzir Cabral, Estádio Municipal Presidente Vargas e Estádio Governador Plácido Castelo - Arena Castelão. Pode ser visualizada a distância em quilômetros de cada bairro em relação a cada um dos três estádios, a legenda dos mapas oferece a percepção de distância a cada $4 \mathrm{~km}$. Notem que o Estádio Elzir Cabral possui a maior assimetria: Enquanto o Presidente Vargas e a Arena Castelão possuem uma distância de no máximo $16 \mathrm{~km}$ entre os bairros, o Elzir Cabral chega a distanciar-se $24 \mathrm{~km}$ comparado a sua oposta extremidade.

A variável distância, que será utilizada no modelo econométrico de Credit Scoring, neste trabalho é calculada através da camada vetorial de pontos mapeadas nesta análise espacial, onde se calcula a distância do bairro em que se localiza o sócio até o bairro de cada um dos três estádios. A média ponderada da distância refere-se à distância média de cada bairro para o bairro onde está localizado o estádio, ponderada pela incidência de sócios em cada bairro.

A média ponderada da distância é de $8,27 \mathrm{~km}, 7,74 \mathrm{~km}$ e 5,52 km para os Estádios Elzir Cabral, Presidente Vargas e Arena Castelão respectivamente. Apesar da assimetria do Elzir Cabral, a grande incidência de sócios na Barra do Ceará e adjacências equilibra a sua média de distância frente às demais praças esportivas. 
Monteiro, V. B., \& Pereira, P. L. V. (2022, jan./abr.). Análise da inadimplência em um programa sócio-torcedor: o uso do credit scoring como ferramenta de gestão esportiva

\section{Modelos de escoragem}

Este tópico abordará aspectos teóricos que compõem as ferramentas de escoragem e irá propor uma estratégia empírica adaptada aos programas de fidelidade no futebol. O surgimento dessas ferramentas deve-se à crescente inclusão da população no mercado de crédito formal, acompanhada da necessidade de instrumentos que avaliem o risco de crédito desses novos clientes. Os modelos de escoragem são amplamente difundidos nas instituições financeiras como instrumento de mensuração do risco de crédito de um cliente, através de atributos pessoais que geram pontuações ou scores. Segundo Chen e Huang (2003), os modelos de escoragem são instrumentos estatísticos que atribuem pontuações às variáveis de decisão de crédito de um proponente, visando a segregação de características que permitam distinguir os bons dos maus pagadores. Para Khemais, Nesrine e Mohamed (2016), através dos modelos de escores, tornase possível a pré-identificação de certos fatores-chave que determinam a probabilidade de inadimplência

Os modelos de escoragem são divididos em credit scoring (ou application scoring) e o behaviour scoring. De acordo com Thomas (2000), credit scoring auxilia na decisão de aprovação ou não do crédito, ou seja, caso o proponente ainda não seja cliente. Já behaviour scoring utiliza informações comportamentais dos clientes, na relação pós-crédito, para auxiliar na gestão e manutenção dos créditos concedidos.

Conforme resume Li, Tian, Zhou e Yang (2017), enquanto o credit scoring é normalmente utilizado para avaliar a aceitação do cliente, ex-ante o crédito, o behaviour scoring avalia o comportamento do cliente ex-post o crédito. A observação de mudanças de comportamento pode ser um sinal de alarme para uma revisão do relacionamento de crédito com o cliente. Para tal, o credit scoring utiliza-se de dados cadastrais, como faixa de renda, faixa de etária, estado civil, quantidade de dependentes, profissão, casa própria ou alugada, além dos bureaus de mercado como Serasa, SPC e o Boa vista, por exemplo. Já o modelo de behaviour scoring apresenta como principais variáveis: número de parcelas, parcelas em atraso, média de atraso, comprometimento do limite de crédito, quantidade de vezes que rotativou a dívida, além dos próprios dados cadastrais. Segundo Pereira (2004, p. 4), por possuírem mais variáveis, os modelos de behaviour scoring apresentam maiores taxas de sucesso.

Segundo Albuquerque, Medina e Silva (2017), para a construção de modelos de escoragem é empregada a técnica de regressão logística, apresentando-se, geralmente, mais 
Monteiro, V. B., \& Pereira, P. L. V. (2022, jan./abr.). Análise da inadimplência em um programa sócio-torcedor: o uso do credit scoring como ferramenta de gestão esportiva

robusta que outras técnicas baseadas em análise multivariada, como, por exemplo, análise discriminante.

Um dos objetivos desses modelos de respostas binárias consiste em estimar a probabilidade de um indivíduo obter sucesso através de um determinado conjunto de atributos. A variável dependente (ou resposta) do modelo é binária, onde diz-se sucesso a identificação do fenômeno que esteja sendo estudado com status 1 (um), caso contrário assume valor zero. Assim sendo, admite-se que se o sócio-torcedor estiver inadimplente, assume valor 1 na base de dados.

Green (2003) afirma que o modelo logit é derivado de uma função de distribuição acumulada logística. A função do modelo logit é dada por:

$$
\operatorname{Prob}\left(y_{i}=1\right)=F\left(X_{i}^{\prime} \beta\right)=L\left(X_{i}^{\prime} \beta\right)=\frac{1}{1+e^{-X_{i}^{\prime} \beta}}
$$

Nessa função a probabilidade assume valores entre 0 e 1 quando $-X_{i}^{\prime} \beta$ varia de $-\infty$ a $+\infty$, respectivamente. O processo de estimação envolve a definição de uma função de máximaverossimilhança utilizada para estimar os parâmetros que maximizam a probabilidade de uma determinada amostra pertencer a uma população, onde, sua forma funcional para o modelo de resposta binária, como o logit, segue:

$$
L=\prod_{i=1}\left[F\left(X_{i}^{\prime} \beta\right)\right]^{y i}\left[1-F\left(X_{i}^{\prime} \beta\right)\right]^{1-y i}
$$

Além disso, para melhor a acurácia do modelo de previsão, será adotado um método de correção de viés de seleção amostral, pelo procedimento de Heckman. Para compreender a formação desse viés, faz-se necessário observar os dois nós de decisão, conforme diagrama da Figura 4. No primeiro momento decide-se entrar ou não no programa sócio-torcedor, em seguida, permanecer ativo ou inadimplente. 


\section{Figura 4.}

Nós de Decisão do Sócio-Torcedor.

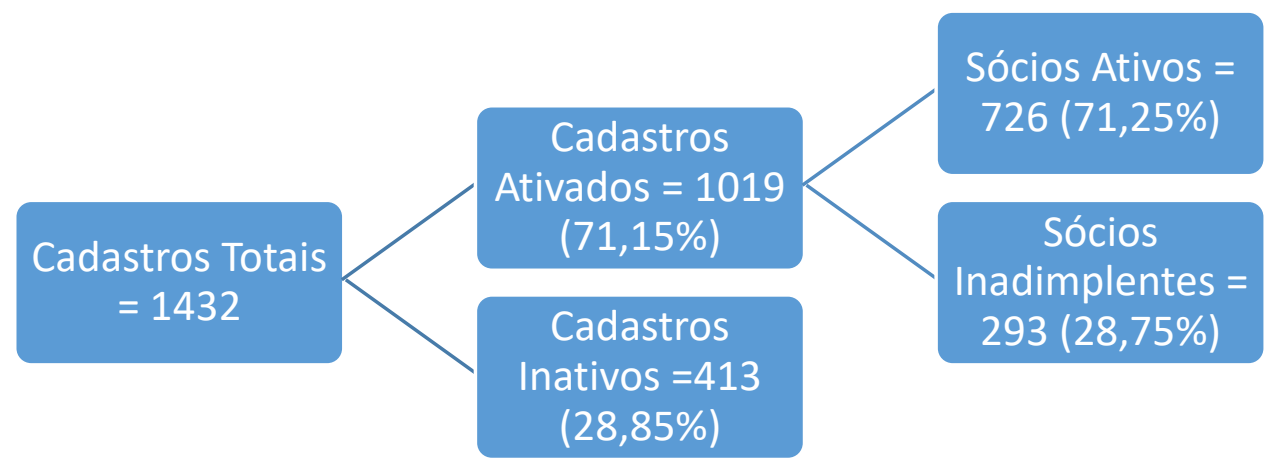

Fonte: Elaboração dos autores.

Observem que a estimação da probabilidade de inadimplência pode ser enviesada por um problema de seleção amostral, haja vista que o grupo de inativos $(28,85 \%)$ possui características diferentes, com perfis de torcedores mais jovens e menor proporção de mulheres (Ver Tabela 1: Todos os planos). O viés consiste na inadimplência populacional estar sub ou superstimada pela ausência desses potenciais sócios. Sendo assim, será feita a estimação em dois estágios: primeiro estima-se a probabilidade de associar-se com os 1432 inscritos, posteriormente se calcula a inversa de mills e inclui-se a mesma na equação principal; feito isso, estima-se a probabilidade de inadimplência com os 1019 sócios da equação principal. Esse procedimento de correção de víes amostral pelo procedimento de Heckman, dentro do contexto do Credit Scoring, foi adotado por Greene (1998), ao citar que o problema de seletividade ocorre devido às amostras geralmente serem baseadas em indivíduos a quem o crédito já foi concedido.

A seguir, a especificação do modelo em dois estágios:

$$
\begin{aligned}
& \text { Eq. } \quad A D E S A ̃ O_{i}=\propto_{0}+\propto_{1} \text { PLANO }_{i}+\propto_{2} \text { DEPEN }_{i}+\propto_{3} \text { IDADE }_{i}+\propto_{4} G \hat{E} N E R O_{i} \\
& \text { Seleção } \quad+\propto_{5} \operatorname{DUMMY}_{\text {FOR }}+\propto_{6} \text { DUMMY }_{\mathrm{FOR}} * \operatorname{DISTÂNCIA}_{i}+v_{i} \\
& 1432
\end{aligned}
$$


A variável dependente do modelo econométrico INADIMP é do tipo binária, e assume valor 1 se o sócio for inadimplente e 0 caso contrário. A variável PLANO é do tipo categórica, assume os seguintes valores: 1 = Campeão Cearense; 2 = Campeão dos Campeões; 3 = Campeão Brasileiro e; 4 = Conselheiro. A variável DEPEN indica 1 se o sócio possui dependentes vinculados (Plano "Tubarãozinho") e 0 caso contrário. A variável IDADE é do tipo quantitativa, calculada como a diferença entre a data de nascimento de cada sócio e o dia 30/04/2020, data da realização do cálculo. A variável GÊNERO é do tipo binária, assume valor 1 caso sexo Masculino e 0 caso sexo Feminino. A variável DUMMY_FOR é do tipo binária, assume valor 1 caso a residência do sócio seja na cidade de Fortaleza e 0 caso contrário. A DISTÂNCIA é uma variável quantitativa, extraída da georreferenciação dos endereços, medida como a distância do bairro que cada sócio reside e o bairro Benfica, onde localiza-se o Estádio Presidente Vargas, local de maior incidência de jogos do Ferroviário. A variável ADESÃO é do tipo binária, e assume valor 1 caso o torcedor tenha concluído a etapa de cadastro e pagamento e adentrado ao programa e, 0 caso não tenha concluído a etapa de pagamento e seu perfil esteja inativo. A variável MILLS representa a inversa de mills, calculada como os valores estimados da variável dependente no modelo de seleção (ADESÃO) e filtradas as observações referentes a equação principal.

\section{Análise de resultados}

O modelo de escoragem para o programa sócio-torcedor do Ferroviário leva em consideração variáveis extraídas na ficha cadastral do associado, logo, conforme apresentado na literatura, tal abordagem trata-se de um Credit Scoring. Já o Behaviour Scoring utiliza variáveis de relacionamento com o cliente, como parcelas em atraso etc. Além disso, a estimação do Credit Scoring é baseada em uma regressão logística com correção de viés de seletividade, conforme discutido por Greene (1998).

Observem na equação principal da Tabela 3 que a variável PLANO possui sinal negativo, ou seja, quanto mais alto o plano de adesão, menor a inadimplência. Em relação à variável IDADE dos sócios, com sinal também negativo, quanto maior a idade, menor a inadimplência. A variável GÊNERO apresenta sinal positivo, indicando que o fato de ser homem aumenta a probabilidade de inadimplência. Aqui vale destacar que as estatísticas descritivas apontavam o contrário, um percentual de inadimplência maior entre as mulheres, também verificado no resultado do modelo não condicional. Porém, considerando o cenário de 
Monteiro, V. B., \& Pereira, P. L. V. (2022, jan./abr.). Análise da inadimplência em um programa sócio-torcedor: 0 uso do credit scoring como ferramenta de gestão esportiva

potenciais sócios, com público mais jovem e com maior proporção de homens, após a correção desse viés de seleção amostral, o modelo precifica a maior inadimplência populacional do grupo masculino.

Tabela 3.

Resultado da Estimação da Regressão Logística Para o Modelo não Condicional e Condicional em Dois Estádios

\begin{tabular}{|c|c|c|c|}
\hline \multirow[t]{2}{*}{ Variável } & \multirow{2}{*}{$\begin{array}{l}\text { Equação não } \\
\text { condicional }\end{array}$} & \multicolumn{2}{|c|}{ Equação condicional (2 Estágios) } \\
\hline & & Eq. Seleção & Eq. Principal \\
\hline CONSTANTE & $\begin{array}{c}-1.202854 * * * \\
(-3.297919)\end{array}$ & $\begin{array}{c}-1.346094 * * * * \\
(-4.199764)\end{array}$ & $\begin{array}{c}7.709814 * * * * \\
(5.472727)\end{array}$ \\
\hline PLANO & $\begin{array}{c}0.247516^{* *} \\
(2.348319)\end{array}$ & $\begin{array}{c}0.923976 * * * * \\
(8.784959)\end{array}$ & $\begin{array}{c}-1.792285 * * * \\
(-5.316983)\end{array}$ \\
\hline DEPEN & $\begin{array}{c}-0.334272 \\
(-1.270953)\end{array}$ & $\begin{array}{c}0.706456 * * \\
(2.194471)\end{array}$ & $\begin{array}{c}-1.583402 * * * \\
(-4.976410)\end{array}$ \\
\hline IDADE & $\begin{array}{c}-0.010352 * * \\
(-2.119568)\end{array}$ & $\begin{array}{l}0.007901 * \\
(1.747600)\end{array}$ & $\begin{array}{c}-0.031957 * * * \\
(-5.160764)\end{array}$ \\
\hline GÊNERO & $\begin{array}{c}-0.097019 \\
(-0.483816)\end{array}$ & $\begin{array}{l}-0.345146^{*} \\
(-1.693434)\end{array}$ & $\begin{array}{c}0.824630^{* * * *} \\
(3.293537)\end{array}$ \\
\hline DUMMY_FOR & $\begin{array}{c}0.119801 \\
(0.461459)\end{array}$ & $\begin{array}{c}0.782154 * * * \\
(3.700641)\end{array}$ & $\begin{array}{c}-2.558214 * * * \\
(-5.400224)\end{array}$ \\
\hline $\begin{array}{l}\text { DUMMY_FOR } \\
\text { *DISTÂNCIA }\end{array}$ & $\begin{array}{c}0.037816 \\
(1.447701)\end{array}$ & $\begin{array}{c}-0.018586 \\
(-0.724830)\end{array}$ & $\begin{array}{c}0.087909 * * * \\
(3.183810)\end{array}$ \\
\hline MILLS & & & $\begin{array}{c}-9.541433 * * * \\
(-6.226284)\end{array}$ \\
\hline $\mathbf{R 2}$ & 0.012595 & 0.092556 & 0.067900 \\
\hline ESTATISTICA LR & 15.39911 & 147.8039 & 83.01832 \\
\hline PROB (ESTAT. LR) & 0.008786 & 0.000000 & 0.000000 \\
\hline
\end{tabular}

*Significância estatística ao nível de 1\%; **Significância estatística ao nível de 5\%; ***Significância estatística ao nível de $10 \%$; ( ) Estatística Z.

Fonte: Elaboração dos autores.

A análise espacial também foi coerente com a literatura. Segundo Bandarra (2017), o SC Internacional aumenta a quantidade de sócios em Porto Alegre-RS quando o clube está em um bom momento esportivo, mostrando que o efeito espacial é relevante na cooptação de sócios. Na presente pesquisa, o fato de ser da cidade de Fortaleza (DUMMY_FOR) reduz a probabilidade de inadimplência e, quanto mais distante do estádio Presidente Vargas 
(DUMMY_FOR *DISTÂNCIA), maior a inadimplência, resultados mostrados nos sinais negativo e positivo para essas variáveis, respectivamente.

O fato do titular da conta possuir dependentes vinculados reduz a probabilidade de inadimplência, mensurado no sinal negativo da variável DEPEN. Esse resultado fortalece os argumentos levantados na literatura, como Xavier (2010) e Llopis-goig (2012), que afirmaram que os torcedores possuem um sentimento de pertencionismo clubístico e, combinado com os argumentos de Derbaix e Decrop (2011), a paixão pelo futebol é um sentimento que passa de pai para filho. Assim, os pais avaliam como seu status de inadimplência pode impactar sobre a influência de laços, hábitos e valores que mantêm com seus filhos e, sobretudo, reforça que a ida aos jogos, principal benefício do sócio-torcedor, é uma atividade familiar, de pais e filhos. Essa constatação torna-se importante para orientar o clube na criação de experiências familiares e incentivar o cadastramento de dependentes no programa.

Além disso, o sinal da inversa de Mills é significativo, apontando existir problema de seleção amostral no modelo proposto, o que justifica o procedimento em dois estágios. Sobre a questão da seletividade amostral, pode-se inferir, pelo fato de existirem perfis diferentes entre os grupos que aderem e não aderem ao programa, que os sinais da equação não condicional estão enviesados em relação aos verdadeiros parâmetros populacionais que explicam a inadimplência. Vale ressaltar o melhoramento do ajustamento do modelo após o procedimento de correção de seletividade amostral pelas estatísticas R2 e LR.

Com base nos resultados obtidos, realizaram-se oito simulações através do efeito marginal do modelo logit, para testar a eficácia do modelo na predição de inadimplência dos clientes/torcedores. A Tabela 4 apresenta o score (probabilidade de inadimplência) de um perfil com a média das variáveis que compõem o modelo e oito cenários hipotéticos. Os cenários 1 a 8 apresentam perfis de um cliente "mau" pagador até um cenário de um cliente "bom" pagador. A definição do "bom" e "mau" consiste nas interpretações dos sinais do modelo econométrico. Por exemplo, IDADE com sinal negativo significa que os mais velhos têm menos probabilidade de inadimplência, ou seja, bons pagadores. Observa-se a redução do score ao longo das simulações, quando os perfis vão se aproximando do melhor cenário (número 8). Para gerar os scores na aplicação do Credit Scoring, deve-se calcular as probabilidades estimadas de inadimplência de cada perfil usando a fórmula:

$$
p=\frac{e^{\beta_{0}+\beta_{i} X}}{1+e^{\beta_{0}+\beta_{i} X}}
$$


Monteiro, V. B., \& Pereira, P. L. V. (2022, jan./abr.). Análise da inadimplência em um programa sócio-torcedor: 0 uso do credit scoring como ferramenta de gestão esportiva

Tabela 4.

Simulações de Scores Através da Metodologia Credit Scoring

\begin{tabular}{|c|c|c|c|c|c|c|c|c|c|}
\hline \multirow{2}{*}{ Variáveis } & \multirow{2}{*}{$\begin{array}{l}\text { Média das } \\
\text { Variáveis }\end{array}$} & \multicolumn{8}{|c|}{ Cenários } \\
\hline & & 1 & 2 & 3 & 4 & 5 & 6 & 7 & 8 \\
\hline PLANO & 2.356564 & 2 & 2 & 2 & 3 & 3 & 3 & 3 & 4 \\
\hline DEPEN & 0.069832 & 0 & 0 & 0 & 0 & 0 & 0 & 0 & 1 \\
\hline IDADE & 43.61978 & 20 & 30 & 40 & 30 & 40 & 50 & 50 & 50 \\
\hline GÊNERO & 0.872207 & 1 & 1 & 0 & 1 & 1 & 1 & 0 & 0 \\
\hline DUMMY_FOR & 0.782123 & 0 & 1 & 1 & 1 & 1 & 1 & 1 & 1 \\
\hline $\begin{array}{l}\text { DUMMY_FOR } \\
\text { *DISTÂNCIA }\end{array}$ & 5.557444 & 0 & 10 & 5 & 10 & 10 & 5 & 2 & 2 \\
\hline Resultado $\mathbf{p}=$ & 0.5903 & 0.9818 & 0.9098 & 0.6744 & 0.6270 & 0.5498 & 0.3637 & 0.3052 & 0.0065 \\
\hline
\end{tabular}

Fonte: Elaboração dos autores.

Notem na Tabela 4 que o modelo se mostrou coerente na predição de inadimplência do cliente "mau" e "bom" pagador. Notem que o cliente "mau" pagador, indicado pelo cenário 1: plano 2, sem dependentes, 20 anos de idade, sexo masculino e residência fora de Fortaleza, apresenta probabilidade de $98 \%$ de inadimplência. A medida que os perfis caminham na direção dos sinais que melhoram a apuração da inadimplência, indicados na estimação do Credit Scoring, as probabilidades de inadimplência diminuem consideravelmente.

\section{Considerações finais}

A indústria do futebol passou nos últimos anos por inúmeras transformações nas suas relações de trabalho, fiscal organizacional e com o torcedor. Como marco dessas modificações podem-se citar a Lei Pelé, o Estatuto do Torcedor e a Lei do Profut. Ao passo que todo o marco regulatório foi avançando no sentido de transformar o futebol brasileiro em uma atividade econômica viável e compatível com a sua dimensão, os clubes foram passando por transformações em direção à profissionalização da gestão. Importantes ferramentas de sucesso no mercado corporativo tradicional foram adaptadas para o segmento futebolístico, como 
Monteiro, V. B., \& Pereira, P. L. V. (2022, jan./abr.). Análise da inadimplência em um programa sócio-torcedor: 0 uso do credit scoring como ferramenta de gestão esportiva

exemplo podem-se citar os programas de fidelização de torcedores, ou programas sóciotorcedor, inspirados em programas de fidelização de operadoras de cartão de crédito etc.

É extremamente desafiador a gestão de um clube de futebol, pois, se por um lado existe o cronograma fixo de execução das despesas, o cronograma das receitas está sujeito à volatilidade do desempenho esportivo. O programa sócio-torcedor visa equilibrar essa equação, garantindo perenidade nas receitas através do conceito de maximização do valor da marca, oferecendo inúmeras vantagens e benefícios para os torcedores fidelizados em troca de mensalidades duradouras.

O objetivo deste trabalho foi compreender o comportamento da inadimplência de torcedores diante de um programa sócio-torcedor, empregando a tecnologia Credit Scoring, tradicionalmente difundida nas instituições bancárias, tomando o Ferroviário Atlético ClubeCE como case deste estudo. A estratégia metodológica da estimação por dois estágios deve-se aos perfis de inativos e ativos serem diferentes, com maiores proporções de jovens e homens nos perfis inativos, e não considerar todo o conjunto de informação poderia enviesar os resultados.

Os resultados apontam que os sócios com planos mais caros, idades mais elevadas, mesma cidade da realização dos jogos e proximidade ao estádio reduzem de forma significativa suas probabilidades de inadimplência. A literatura aponta, como em Bandarra (2017), que a localização influencia o comportamento dos torcedores, pois aumenta a proporção de sócios do SC Internacional na cidade de Porto Alegre quando melhora o desempenho da equipe. Além disso, o modelo foi testado auferindo a predição da inadimplência do cliente "mau" e "bom" pagador, evidenciando-se nas simulações dos scores gerados que, quando melhoram os perfis, de acordo com os sinais estimados pelo modelo, menores são as probabilidades de inadimplência.

A análise de gênero trouxe um resultado que desperta para sugestões de trabalhos futuros, pois, tratando-se de um ambiente de maioria masculina, 87,2\% da base de dados em estudo, o sexo feminino apresentou-se com menor probabilidade de inadimplência.

Com esse resultado é possível deduzir algumas hipóteses: i) Alta correlação com esposas de sócios e, por sua vez, sócios que cadastram suas esposas podem estar correlacionados com um maior nível de renda ou; ii) As torcedoras são menos voláteis aos resultados esportivos das equipes ou; iii) As mulheres são mais adimplentes que os homens. Segundo Mulheres (2016), referente a um estudo da Serasa Experian que utilizou uma amostra de 2 milhões de consumidores em 2016, o público feminino apresentou a renda menos 
Monteiro, V. B., \& Pereira, P. L. V. (2022, jan./abr.). Análise da inadimplência em um programa sócio-torcedor: 0 uso do credit scoring como ferramenta de gestão esportiva

comprometida com as instituições financeiras: $26,8 \%$ das entrevistadas não têm comprometimento, enquanto $24,6 \%$ do grupo masculino estão nessa condição.

Outro resultado interessante da pesquisa refere-se aos dependentes. $\mathrm{O}$ fato do titular do plano de sócios possuir dependentes vinculados a sua conta diminui a probabilidade de inadimplência, se contrapondo a literatura de Credit Scoring bancário, onde o número de dependentes aumenta a probabilidade de inadimplência, como mostrado em Bücker, Kampen, e Krämer (2013) e Dinh e Kleimeier (2007). As hipóteses desse resultado se pautam nos aspectos sentimentais nas relações entre pais e filhos, onde os pais sempre buscam repassar valores e hábitos para seus descendentes.

Por fim, a limitação da pesquisa encontra-se na possibilidade de inclusão de novas variáveis e novos contextos regionais, expandindo o modelo para um Behaviour Scoring, com a sugestão de inclusão de variáveis que possam refletir a fase esportiva do clube na temporada, além das variáveis de relacionamento com o programa.

\section{Referências}

Albuquerque, P. H. M., Medina, F. A. S., \& Silva, A. R. D. (2017). Regressão Logística Geograficamente Ponderada Aplicada a Modelos de Credit Scoring. Revista Contabilidade \& Finanças, 28, 93-112.: https://doi.org/10.1590/1808-057x201703760

Azevedo, A. G. D. (2013). O desenvolvimento de estratégia do programa Sócio-torcedor relacionado com a visão Gerencial do futebol profissional no Distrito Federal. (Dissertação de mestrado, Universidade de Brasília). https://repositorio.unb.br/handle/10482/14362

Bandarra, T. M. D. S. (2017). Sport Club Internacional: uma análise de seus torcedores com uma abordagem de CRM. (Trabalho de conclusão de curso, Universidade Federal do Rio Grande do Sul). https://www.lume.ufrgs.br/handle/10183/170502

Biscaia, R., Ross, S., Yoshida, M., Correia, A., Rosado, A., \& Marôco, J. (2016). Investigating the role of fan club membership on perceptions of team brand equity in football. Sport Management Review, 19(2), 157-170. https://doi.org/10.1016/j.smr.2015.02.001

Bücker, M., van Kampen, M., \& Krämer, W. (2013). Reject inference in consumer credit scoring with nonignorable missing data. Journal of Banking \& Finance, 37(3), 10401045. https://doi.org/10.1016/j.jbankfin.2012.11.002 
Monteiro, V. B., \& Pereira, P. L. V. (2022, jan./abr.). Análise da inadimplência em um programa sócio-torcedor: 0 uso do credit scoring como ferramenta de gestão esportiva

Carvalho, W. G., Molletta, S. R., Stinghen, F. M., \& Knaut, C. M. F. (2013). Estudo sobre a satisfação do sócio-torcedor do Paraná Clube. Revista Intercontinental de Gestão Desportiva, 3. https://doi.org/10.51995/2237-3373.v11i1e110011

Chen, M. C., \& Huang, S. H. (2003). Credit scoring and rejected instances reassigning through evolutionary computation techniques. Expert Systems with Applications, 24(4), 433-441. https://doi.org/10.1016/S0957-4174(02)00191-4

Cunha, Michele Aparecida. (2021). Finanças e Regionalidade: um modelo de Credit Scoring com uso da Regressão Logística Geograficamente Ponderada no Programa Minha Casa Minha Vida em Minas Gerais. 2021. 95 f. Dissertação (Mestrado em Administração) - Universidade Federal de Uberlândia, Uberlândia, 2021. DOI http://doi.org/10.14393/ufu.di.2021.73

DeSarbo, W. S. (2010). A spatial multidimensional unfolding choice model for examining the heterogeneous expressions of sports fan avidity. Journal of Quantitative Analysis in Sports, 6(2). https://doi.org/10.2202/1559-0410.1232

Derbaix, C., \& Decrop, A. (2011). Colours and scarves: an ethnographic account of football fans and their paraphernalia. Leisure Studies, 30(3), 271-291. https://doi.org/10.1080/02614367.2010.527356

Dinh, T. H. T., \& Kleimeier, S. (2007). A credit scoring model for Vietnam's retail banking market. International Review of Financial Analysis, 16(5), 471-495. https://doi.org/10.1016/j.irfa.2007.06.001

Fleury, F. A., Brashear-Alejandro, T., \& Feldmann, P. R. (2014). Considerações teóricas acerca do composto de marketing esportivo. PODIUM Sport, Leisure and Tourism Review, 3(1), 01-11. https://doi.org/10.5585/podium.v3i1.82

Gomes, E. F. C. (2014). O que se pode extrair da média de público histórica do clube. Almanaque do Ferrão. https://almanaquedoferrao.net/2014/11/26/o-que-se-podeextrair-da-media-de-publico-historica-do-ferrao/

Greene, W. (1998). Sample selection in credit-scoring models. Japan and the world economy, 10(3), 299-316. https://doi.org/10.1016/S0922-1425(98)00030-9

Greene, W. H. (2003). Econometric analysis. Pearson Education India.

Hamil, S., Walters, G., \& Watson, L. (2013). The model of governance at FC Barcelona: balancing member democracy, commercial strategy, corporate social responsibility and sporting performance. Who Owns Football? 143-172. Routledge. https://doi.org/10.1080/14660971003780446

Khemais, Z., Nesrine, D., \& Mohamed, M. (2016). Credit scoring and default risk prediction: A comparative study between discriminant analysis \& logistic regression. International Journal of Economics and Finance, 8(4), 39. https://doi.org/10.5539/ijef.v8n4p39 
Monteiro, V. B., \& Pereira, P. L. V. (2022, jan./abr.). Análise da inadimplência em um programa sócio-torcedor: 0 uso do credit scoring como ferramenta de gestão esportiva

Leal, D. (2011). Vasco luta contra inadimplência de 83\% dos sócios. Portal Lance. https://www.lance.com.br/todos-esportes/vasco-luta-inadimplencia-socios.html

Lei $n^{\circ}$ 9.615, de 24 março de 1998. Institui normas gerais sobre desporto e dá outras providências. http://www.planalto.gov.br/ccivil_03/leis/19615consol.htm

Lei $\mathrm{n}^{\circ} 10.671$, de 15 de maio de 2003. Dispõe sobre o Estatuto de Defesa do Torcedor e dá outras providências. http://www.planalto.gov.br/ccivil_03/leis/2003/110.671.htm

Li, Z., Tian, Y., Li, K., Zhou, F., \& Yang, W. (2017). Reject inference in credit scoring using semi-supervised support vector machines. Expert Systems with Applications, 74, 105114. https://doi.org/10.1016/j.eswa.2017.01.011

Llopis-Goig, R. (2012). From "socios" to "hyper-consumers": an empirical examination of the impact of commodification on Spanish football fans. Soccer \& Society, 13(3), 392408. https://doi.org/10.1080/14660970.2012.655508

Macri, M. (2011). Pasión y gestión: Claves del ciclo Macri en Boca. Aguilar.

Moreira, M. V., \& Hijós, N. (2013). Clubes deportivos, fútbol y mercantilización: los casos de Boca Juniors e Independiente en la Argentina. Question, 1(37), 149-162. https://www.perio.unlp.edu.ar/ojs/index.php/question/article/view/1728/1473

Mulheres são menos inadimplentes do que homens. (2016). Consumidor Moderno. https://www.consumidormoderno.com.br/2016/03/08/mulheres-sao-menosinadimplentes-do-que-homens/

Pereira, G. H. D. A. (2004). Modelos de risco de crédito de clientes: Uma aplicação a dados reais. (Dissertação de doutorado, Universidade de São Paulo). https://doi.org/10.11606/D.45.2004.tde-28122004-224257

Ribeiro, L. C. (2012). Futebol: por uma história política da paixão nacional. História: Questões \& Debates, 57(2). http://dx.doi.org/10.5380/his.v57i2.30570

Rosolino, T. (2020). As dívidas dos times brasileiros: veja ranking com balanço dos maiores clubes. Portal Terra. https://www.goal.com/br/not\%C3\%ADcias/as-dividas-dostimes-brasileiros-veja-ranking-com-balanco/14a81mxtoco6ilirhwp9kec53x

Silva Leal, G., Furin, L. M., Conejero, M. A., André, P., \& Bougleux, V. (2017) Programas Sócio-Torcedor no Brasil-Análise comparativa entre clubes selecionados e o Volta Redonda Futebol Clube. Revista Gestão e Negócios do Esporte.

Souza Dias, P., Monteiro, P. R. R., \& Ribeiro, E. M. S. (2019). Aplicação de Redes Bayesianas para análise de programas sócio torcedor. Revista Pensamento Contemporâneo em Administração, 13(2), 49-66. https://doi.org/10.12712/rpca.v13i2.27526 
Thomas, L. C. (2000). A survey of credit and behavioural scoring: forecasting financial risk of lending to consumers. International journal of forecasting, 16(2), 149-172. https://doi.org/10.1016/S0169-2070(00)00034-0

Umbelino, W. L., Silva, R. B., Ponte, V. M. R., \& Lima, M. C. (2019). Disclosure em Clubes de Futebol: Estudo sobre os Reflexos da Lei do PROFUT. Revista Evidenciação Contábil \& Finanças, 7(1), 112-132. https://doi.org/10.22478/ufpb.2318$1001.2019 \mathrm{v} 7 \mathrm{n} 1.38074$

Xavier, F. (2010). O Programa "Sócio-Torcedor" do Sport Club Internacional. Aurora. Revista de Arte, Mídia e Política, (9), 128-138. https://revistas.pucsp.br/aurora/article/view/3788

Yang S, Yu SL(K), Bruwer J. (2017) The effectof relational benefits in loyalty programmes: Evidence from Chinese milk formula customer clubs. J Consumer Behav.2018;1-10. https://doi.org/10.1002/cb.1705 